\title{
Food Proteins as a Tool in Human Longevity: A Mini-Review
}

ISSN: 2640-9208

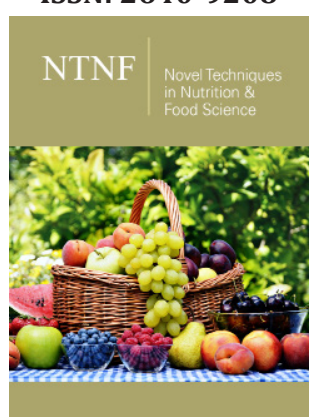

*1 Corresponding author: Olga Luisa Tavano, Faculty of Nutrition, Federal University of Alfenas, Minas Gerais, Brazil, Email: mailto:tavanool@yahoo.com.br

Submission: 酒 October 26, 2019

Published: 韭 November 01, 2019

Volume 4 - Issue 3

How to cite this article: Olga L Tavano, Sinézio I da Silva Júnior. Food Proteins as a Tool in Human Longevity: A MiniReview. Nov Tech Nutri Food Sci. 4(3). NTNF.000590.2019.

DOI: 10.31031/NTNF.2019.04.000590

Copyright@ Olga Luisa T, Sinézio I S. This article is distributed under the terms of the Creative Commons Attribution 4.0 International License, which permits unrestricted use and redistribution provided that the original author and source are credited.

\author{
Olga Luisa Tavano ${ }^{1 *}$ and Sinézio Inácio da Silva Júnior ${ }^{2}$ \\ ${ }^{1}$ Faculty of Nutrition, Federal University of Alfenas, Minas Gerais, Brazil \\ ${ }^{2}$ School of Pharmaceutical Sciences, Federal University of Alfenas, Minas Gerais, Brazil
}

\begin{abstract}
Demographic transition and interest in human longevity increasingly guide studies on the best quality of the human diet, a factor directly related to the lifespan. As the world's population is aging, with more people over 65, dietary recommendations specific to this context should be discussed and adopted. Proteins are related to this theme both for their fundamental role as nutrients, but also as nutraceutical potentials that act not only for the maintenance of health, but for the prolongation of life. Thus, there is also a growing interest in research on the effects of ingestion of peptides with different bioactivities.
\end{abstract}

Keywords: Longevity; Older people; Elderly; Lifespan; Protein intake; Bioactive peptides

\section{Introduction}

Human longevity is a highly complex phenomenon influenced by a variety of social, cultural, environmental, genetic and epigenetic factors that isolated or associated influence the duration of human life. Due to the demographic transition, the percentage of people over 65 has increased and the idea of living beyond 120 is not a distant utopia, as discussed by Finkel [1]. To reach an extremely advanced age, genetics is gaining relevance considering that dysregulation of transcription and chromatin networks is probably a strategic target. In this sense, so-called epigenetic diets can be an important contribution to healthy aging and longevity and human proteins deserve a prominent role [2]. Many evidence-based studies recognize nutrition as a key factor in life extension [3-5]. Proteins are important dietary factors associated with maintaining life, promoting health both for its nutrient performance and for its nutraceutical potential.

\section{Nutritional aspects}

Life expectancy and metabolic health are strongly influenced by dietary interventions [6], whereas in this context the control of the quantity and quality of protein intake is of great impact [7]. For example, evidence-based studies indicate that protein supplementation may help prevent sarcopenia, an age-related decrease in muscle mass and performance [8]. Richter et al. [9] discuss the need to adopt differentiated reference values when it comes to protein intake for older people, and they indicate the need to adopt a reference value of $1.0 \mathrm{~g}$ protein/ $\mathrm{kg}$ body weight per day for adults $>65$ years, above $0.8 \mathrm{~g}$ protein $/ \mathrm{kg}$ bw/day currently recommended for adults of any age. This differentiated protein intake would be recommended to prevent sarcopenia [10] and to promote better disability trajectories in the elderly. Mendonça et al. [11] present data that suggest further progress in this discussion, opening the need for perhaps considering the division into more age groups to establish recommendations specific to each need. When they determined a relationship between protein intake and disability for adults older than 85 years, they found that higher protein intake (such as $1.0 \mathrm{~g} / \mathrm{kg}$ body weight/day or higher) was associated with lower protein intake and development of disability in older adults Houston et al. [12], when studying the relationship of protein intake by adults between 70 and 79 years and their loss of lean mass, found that those who consumed an average of $1.1 \mathrm{~g} / \mathrm{kg} /$ day lost $40 \%$ less lean mass than those averaged $0.8 \mathrm{~g} / \mathrm{kg}$ bw $/$ day. The PROT-AGE Study Group highlight two important recommendations for healthy older adults (>65): "To maintain and regain muscle, older people should consume an average daily intake in the range of 1.0 to $1.2 \mathrm{~g} / \mathrm{kg}$ bw/d", and still: " 25 to $30 \mathrm{~g}$ protein per meal, containing about 
2.5 to 2.8 g leucine" [13]. But while some studies cite increased leucine intake as positive, caution is needed, as others associate high dietary BCAA as a cardiometabolic risk [14]. Not only can the intake of some specific amino acids be considered, but the ratio between them seems to be important to lifespan.

Romano et al. [15] pointed out that an adequate intake of essential and non-essential amino acids is crucial for preserving cellular integrity and healthy whole-body metabolism in mice. They observed that different proportions of essential and non-essential, limiting essential or exceeding non-essential, may increase or decrease lifespan, and high or unbalanced non-essential amino acids intake provided by food proteins can be detrimental to life expectancy. It is important to highlight that the issue of protein consumption should be better discussed, since the influence of food matrix interaction has been briefly explored and may bring new considerations about the benefits of the protein sources themselves [7]. Some authors, for example, already approach plant-based proteins in this context, highlighting the advantages of these proteins in the context of their matrix [16].

\section{Nutraceutical aspects}

Although the classic nutritional aspect of the proteins has been present in the majority of studies that provided evidence about relationship protein and healthy lifespan, the nutraceutical contribution of proteins is important too. Intact proteins and free amino acids may have impact functions on our metabolism, but peptides have shown greater potential for bioactivity. Compared to intact proteins, peptides have the advantage that they can be absorbed into the human gut and penetrate cells where their function could be performed. Bioactive peptides have been demonstrating their potential for positive interference in human metabolism, both in a curative and preventive axis of different metabolic aspects that may be directly or indirectly linked to life expectancy. In general, bioactive peptides are short food protein sequences composed mainly of 2 to 20 amino acid residues and it is these protein-derived molecules that can have metabolic and "epigenetic effect $[17,18]$."

The delivery of peptides may be in different ways, including release during natural digestion of foods or oral administration of peptides synthesized or obtained by hydrolysis of different protein sources. They can be absorbed through the small-intestinal epithelium by passive diffusion mechanisms, carrier-mediated transport via PEPT1, endocytosis or paracellular mechanisms [19]. The application of bioactive peptides as health promoters has been highlighted, among other advantages, they are considered natural agents with low toxicity. Different bifunctionalities have been demonstrated in in vitro and in vivo studies. Many of them closely related to the promotion of human longevity. Following are some of these potential peptide bioactivities:

a) Antihypertensive peptides- The antihypertensive activity of peptides is one of the most cited in the literature, and these peptides have appropriate sequences to inhibit angiotensin-I converting enzyme (ACE-I), an enzyme of the renin angiotensin system. This inhibition promotes an important regulation of the cardiovascular function and blood pressure by both competitive and non-competitive modes. Peptides with few amino acids, and with
$\mathrm{N}$-terminal containing leucine, isoleucine and valine, and/or C-terminal with aromatic amino acids have been pointed as the most active [20].

b) Antioxidant peptides- peptides may have antioxidant activity. Although the exact mechanism for this function is unclear, it is suggested that its action is due to different mechanisms such as: inhibition of singlet oxygen-quenching potential, harmful lipid oxidation, free radical scavenging, and/or chelation of metal ions. Antioxidants can neutralize the deleterious effect of the excess of free radicals which can produce negative effects on human health, such as damage in proteins and cell membranes or DNA mutations. Characteristics like hydrophobic amino acids in their N-terminal regions and/or the presence of Cys, Met, His, Phe, Trp and Tyr may favor the antioxidant properties [21,22].

c) DPP-IV inhibitors- Many peptides present as potential as inhibitors of the dipeptidyl peptidase IV, an enzyme involved in the regulation of serum glucose, this is, in the control of type 2 diabetes in humans. In general, hydrophobic amino acids are present in DPPIV inhibitory peptides, what increase the interaction with the active site of DPP-IV [23].

d) Anti-cancer peptides- Some peptides have the ability to induce cytoplasmic membrane disruption, both through micellization and pore opening, inducing apoptosis. The cationic characteristic has been found among the most potent [24].

e) Neuroprotective peptides- Some peptides can help maintain a healthy brain by contributing to the maintenance of cognitive functions, which would be an important factor in preventing the cognitive impairment or dementia, debilitating age-related disorders. Considering that brain neurogenesis decreases during ageing, peptides that induced proliferation and increased survival and maturation of neural progenitor cells into neurons could prevent age-related cognitive decline [25].

f) Anti-inflammatory properties- Peptides have been studied as possible anti-inflammatory agents. Considering that chronic inflammation may be related to causes of life-shortening illnesses, such as obesity, type-2 diabetes or cardiovascular diseases, but chronic use of anti-inflammatory drugs may lead to side effects such as functional renal impairment in elderly subjects [26]. The application of these peptides can be of great importance. Many anti-inflammatory peptides contain positively charged amino acids, such as Arg and Lys, especially at their C- or N-terminus, and prominent hydrophobicity, which is a major factor associated with their anti-inflammatory potential [27].

g) Antithrombotic peptides- Peptides can present anticoagulant activity. A classic example is the hirudin an anticoagulant peptide produced in the salivary glands of leech, able to bind on thrombin and avoiding the cleavage of fibrinogen and the formation of the fibrin clot [28]. If well administered, they can help in the treatment of thrombotic diseases [29].

h) Multifunctional properties- The same peptide may have the ability to exert more than one benefit to human health. For example, with respect to the prevention of cardiovascular disease, the peptides may be hypocholesterolemia and antidiabetic, or further 
accumulate functions such as lumazine, which is hypocholesterolemia, antioxidant and anti-inflammatory [30].

\section{Conclusion}

Specific recommendations for age subgroups over 65 may be useful for the prevention of lifelong disabilities of older people. Research evidence indicates that an intake of at least $1 \mathrm{~g}$ protein/ $\mathrm{kg}$ body weight/day is significantly beneficial for healthy longevity. It is useful to guide protein intake considering its balance between essential and nonessential amino acids and even the potential for release and absorption of bifunctional peptides during digestion. Bifunctional peptides may play an important role in preventing diseases such as cancer, cardiovascular disease, and which both threaten the duration of life and may impair its quality.

\section{References}

1. Finkel T (2019) The enlightenment of age. Nature 573: 193-194.

2. Morris BJ, Willcox BJ, Donlonb TA (2019) Genetic and epigenetic regulation of human aging and longevity. Biochim Biophys Acta Mol Basis Dis 1865(7): 1718-1744.

3. Abbot A (2018) Reduced-calorie diet shows signs of slowing ageing in people. Nature 555(7698): 570-571.

4. Costa D, Scognamiglio M, Fiorito C, Benincasa G, Napoli C (2019) Genetic background, epigenetic factors and dietary interventions which influence human longevity. Biogerontology 20(5): 605-626.

5. Chrysohoou C, Stefanadis C (2019) Longevity and diet. Myth or pragmatism? Maturitas 76(4): 303-307.

6. Kitada M, Ogura Y, Monno I, Koya D (2019) The impact of dietary protein intake on longevity and metabolic health. EBioMedicine 43: 632-640.

7. Burd NA, McKenna CF, Salvador AF, Paulussen KJM, Moore DR (2019) Dietary protein quantity, quality, and exercise are key to healthy living: a muscle-centric perspective across the lifespan. Front Nutr 6: 83 .

8. Beasley JM, Shikany JM, Thomson CA (2013) The role of dietary protein intake in the prevention of sarcopenia of aging. Nutr Clin Pract 28(6): 684-690.

9. Richter M, Baerlocher K, Bauer JM, Elmadf I, Heseker H, et al. (2019) Revised reference values for the intake of protein. Ann Nutr Metab 74(3): 242-250.

10. Phillips SM (2017) Determining the protein needs of "older" persons one meal at a time. Am J Clin Nutr 105(2): 291-292.

11. Mendonça N, Granic A, Hill TR, Siervo M Mathers JC, et al. (2019) Protein intake and disability trajectories in very old adults: The Newcastle 85+ study. J Am Geriatr Soc 67(1): 50-56.

12. Houston DK, Nicklas BJ, Ding J, Harris TB, Tylavsky FA, et al. (2008) Dietary protein intake is associated with lean mass change in older, community-dwelling adults: The health, ageing, and body composition (Health ABC) study. Am J Clin Nutr 87(1): 150-155.

13. Bauer J, Jentoft AJC, Morley JE, Phillips S, Sieber C, et al. (2013) Evidencebased recommendations for optimal dietary protein intake in older people: A position paper from the PROT-AGE study group. J Am Med Dir Assoc 14(8): 542-559.
14. White PJ, Newgard CB (2019) Branched-chain amino acids in disease. Science 363(6427): 582-583.

15. Romano C, Corsetti G, Flati V, Pasini E, Picca A, et al. (2019) Influence of diets with varying essential/nonessential amino acid ratios on mouse lifespan. Nutrients 11(6): E1367.

16. Lonnie M, Hooker E, Brunstrom JM, Corfe BM, Green MA, et al. (2018) Protein for life: review of optimal protein intake, sustainable dietary sources and the effect on appetite in ageing adults. Nutrients 10(3): E360.

17. Bhandari D, Rafiq S, Gat Y, Gat P, Waghmare R, et al. (2019) A review on bioactive peptides: physiological functions, bioavailability and safety. Int J Pept Res Ther 3: 1-12.

18. Chalamaiaha M, Ulug SK, Hong H, Wu J (2019) Regulatory requirements of bioactive peptides (protein hydrolysates) from food proteins. J Func Foods 58: 123-129.

19. Williams WMM, Stevens BR, Moughan PJ (2014) Are intact peptides absorbed from the healthy gut in the adult human? Nutr Res Rev 27(2): 308-329.

20. Premkumar J, Malini M, Joshy VA (2019) A critical review on food protein derived antihypertensive peptides. Drug Inv Today 12(3): 474-479.

21. Tavano OL, Murcia AB, Secundo F, Lafuente RF (2018) Biotechnological applications of proteases in food technology. Compr Rev Food Sci Food Saf 17(2): 412-436.

22. Nwachukwu ID, Aluko RE (2019) Structural and functional properties of food protein-derived antioxidant peptides. J Food Biochem 43(1): 1-13.

23. Nongonierma AB, FitzGerald RJ (2017) Features of dipeptidyl peptidase IV (DPP-IV) inhibitory peptides from dietary proteins. J Food Biochem 43(1): 1-11.

24. Aaghaz S, Gohe V, Kama A (2019) Peptides as potential anticancer agents. Curr Top Med Chem 19(17): 1491-1511.

25. Katayama S, Nakamura S (2019) Emerging roles of bioactive peptides on brain health promotion. Int J Food Sci Technol 54(60): 1949-1955.

26. Henry D, Page J, Whyte I, Nanra R, Hall C (1997) Consumption of nonsteroidal anti-inflammatory drugs and the development of functional renal impairment in elderly subjects. Results of a case-control study. Br J Clin Pharmacol 44(1): 85-90.

27. Guha S, Majumder K (2019) Structural-features of food-derived bioactive peptides with anti-inflammatory activity: A brief review. J Food Biochem 43(1): $1-14$

28. Krstenansky JL, Owen TJ, Yates MT, Mao SJT (1987) Anticoagulant peptides. Nature of the interaction of the C-terminal region of hirudin with a noncatalytic binding site on thrombin. J Med Chem 30(9): 16881691.

29. Cheng S, Tu M, Liu H, Zhao G, Du M (2019) Food-derived antithrombotic peptides: Preparation, identification, and interactions with thrombin. Crit Rev Food Sci Nutr 59(sup1): S81-S95.

30. Lammi C, Aiello G, Boschin G, Arnoldi A (2019) Multifunctional peptides for the prevention of cardiovascular disease: A new concept in the area of bioactive food-derived peptides. J Func Foods 55: 135-145. 